\title{
Arbor
}

\section{El padre Pedro Páez. El primer viajero europeo conocido que cruzó el sur de Arabia}

\section{Montserrat Mañé Rodríguez}

Arbor CLXXX, 711-712 (Marzo-Abril 2005), 595-616 pp.

A finales del siglo XVI, la ruta portuguesa hacia las Indias la seguían principalmente soldados, comerciantes y misioneros. El padre Páez fue uno de ellos. Apresado por los turcos en las costas de Arabia cuando navegaba hacia Etiopía, fue el primero que cruzó el valle del Hadramaut hasta llegar a la ciudad de San'a y, cuando por fin llegó a Etiopía siete años después, alcanzó a ver las fuentes del Nilo Azul. En ambos casos fue el primero que dejó constancia escrita de todo lo que vio.

\section{Introducción}

Pedro Páez, un gran olvidado hasta hace muy poco tiempo ${ }^{1}$, es conocido principalmente por su labor misionera en Etiopía y, en especial, por ser el primer europeo del que se sabe, o que al menos dejó mención escrita de ello, que alcanzó a ver las fuentes del Nilo Azul. Esa gran meta, que tantos exploradores buscaron y que algunos se adjudicaron faltando a la ver$\mathrm{dad}^{2}$, ha sido uno de los símbolos de los viajes exploratorios llevados a cabo en África durante los siglos XVIII y XIX, aunque ya los antiguos griegos y romanos se aventuraron Nilo arriba en busca de sus fuentes ${ }^{3}$.

Conocer el origen del río Nilo parecía un asunto de mayor trascendencia que cualquier otro descubrimiento y llenó las mentes y la imaginación de muchos autores y exploradores, empujándoles a seguir sus 
orillas o a intentar alcanzarlo desde las costas africanas. Algo que para Pedro Páez resultaba una curiosidad interesante, pero nada importante en sí. Hombre de sentido común, nunca se dejó llevar por las vanidades de este mundo y sí por la que consideraba la labor más importante, la predicación cristiana con la palabra y con el ejemplo. El resto de su vida, las penalidades que pasó, sus viajes, sus estudios, su determinación y entrega, todo lo dio por bien empleado en servicio de su fe. Y logró mucho en un tiempo muy corto, algo más de diecinueve años en Abisinia, aunque sus sucesores en la misión lo echaran todo a perder en menos tiempo aún ${ }^{4}$.

Pero su labor misionera o su testimonio de África no fueron el único legado que nos dejó. Previamente había pasado una serie de años viajando por otros territorios, de grado o por fuerza, que sirvieron también a su formación física y espiritual, o al menos de ese modo los tomó él, que sacaba siempre el máximo partido de lo que le acontecía.

De sus viajes y de su trabajo, así como de todo lo que le rodeaba -fue un gran observador, en el sentido más objetivo del término-, dejó testimonio escrito en su Historia Aethiopiae, documento igualmente relegado al olvido hasta comienzos del siglo XX, aunque esporádicamente se le mencionara. También el padre Emmanuel d'Almeyda dejó un retrato de su persona y de su historia en la segunda mitad del siglo XVII ${ }^{5}$, del que tomaron nota futuros viajeros y exploradores. Pero el "fracaso» que supuso la expulsión de los jesuitas de Etiopía en 1633, once años después de la muerte de Pedro Páez, hizo o contribuyó en gran manera a que su vida y su labor permanecieran en gran parte en el anonimato, excepto para los miembros de su orden, que a menudo tomaron su vida como ejemplo en su labor misionera.

\section{Su vida}

Pedro Páez Xaramillo nació en 1564 en La Olmeda de la Cebolla ${ }^{6}$, entonces perteneciente a Toledo. Parece ser que era de buena familia, adinerada y noble, lo que le permitiría una buena formación, pues, aunque apenas se conocen datos de sus primeros años de vida, su evolución posterior y la aplicación que hizo de sus conocimientos nos lo confirman así. Las lenguas, las ciencias, el arte, la lucha con espada y otras armas, el ser un buen jinete, su educación e incluso su talento en arquitectura nos hablan no sólo de una gran inteligencia y capacidad de asimilación, sino de un aprendizaje previo a los difíciles años que pronto hubo de pasar en 
El padre Pedro Páez. El primer viajero europeo conocido...

su aventura en Oriente. Su buen estado físico que podría responder a la naturaleza, pero también a una buena economía familiar en lo que a la alimentación y a la salud se refiere, añade algún indicio de lo que debieron ser sus años de niñez y mocedad.

Siendo muy joven aún marchó a estudiar a Coimbra, al Colegio das Artes de los jesuitas, cuyos métodos de enseñanza y sus ideas progresistas influirían vivamente en el espíritu de Páez, que pronto vio despertar su vocación religiosa. Por aquellos años Felipe II ya reinaba sobre España y Portugal -como Felipe I- tras la muerte de Enrique I (1580), unión que continuaría hasta 1640, años después de la muerte de Páez. De Coimbra pasó a Belmonte, relativamente cerca de Olmeda, donde conoció al padre Tomás de Ituren, uno de sus profesores de filosofía, que se convertiría en su mentor y amigo y con el que mantendría correspondencia durante toda su vida. Esas cartas serán, junto a su libro, una de las mayores fuentes de información que se tendrán de él.

Una vocación tan temprana encontró también pronto un destino: las misiones. Páez, sin acabar sus estudios y antes de ser ordenado sacerdote, solicitó al general de la Compañía de Jesús que se le enviara a las misiones de Oriente. De este modo, en 1588 partía de Lisboa hacia Goa, en la India, entonces una floreciente ciudad en la que los jesuitas y otras órdenes religiosas tenían casa y actuaban de intermediarios con otros enclaves aún más lejanos ${ }^{7}$. Su primera intención o al menos interés se cifraba en llegar al Japón y a China, pero tras una estancia de varios meses en Goa, en los que aceleró sus estudios con la intención de ser nombrado sacerdote en poco tiempo y en la que no dejó de atender a prisioneros, enfermos y necesitados en general, fue requerido por el provincial de su orden, quien, a instancias de sus superiores y en último término de Felipe II, le preguntó si querría servir al Señor igualmente en la misión de Etiopía, donde hacía años que no lograba entrar ningún misionero y los que quedaban habían disminuido en número y eran ya mayores. Páez, siempre de espíritu animoso y servicial, aceptó encantado el nuevo destino y, en compañía del veterano Antonio de Montserrat, partió de Goa en febrero de $1588^{8}$, según deja constancia en su libro.

La ruta a seguir debía bordear la costa india hacia el norte para después contornear el sur de Arabia y por el mar Rojo alcanzar el puerto de Massawa. Pero la presencia turca, que vigilaba estrechamente la zona con amenaza de muerte para cualquier cristiano, hizo que se retrasara la salida una y otra vez y que finalmente fueran delatados y apresados cuando se dirigían a la costa somalí. 
598

Montserrat Mañé Rodríguez

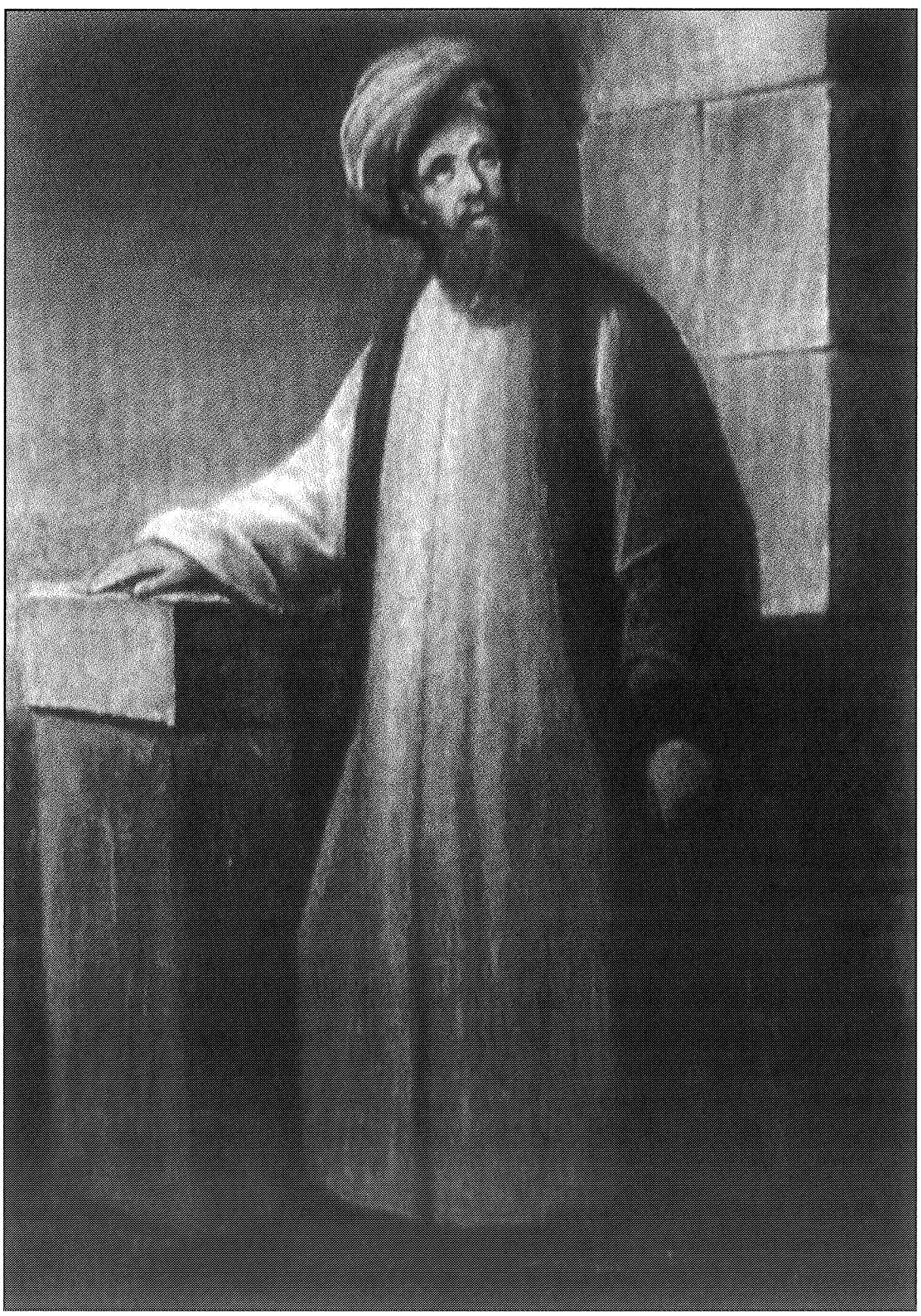

Figura 1. Retrato al óleo de Pedro Páez

(Santuario de Loyola, Guipúzcoa) 
El padre Pedro Páez. El primer viajero europeo conocido...

Aquí comienza su aventura en Arabia de la que tan poco eco se han hecho quienes se interesan por viajes y descubrimientos. Un viaje que duró siete largos años en los que a costa de sus sufrimientos nos dejaron testimonio de una parte de Arabia, la región del Hadramaut, que permaneció desconocida para Europa hasta bien entrado el siglo $\mathrm{XX}^{9}$. Su cautiverio les llevó al puerto de Dhofar, en la costa de Omán, de donde fueron remitidos a un pequeño rey del interior del Hadramaut. Sería uno de los viajes más duros, cruzando el desierto, con apenas agua y comida, andando tras los camellos la mayor parte del tiempo y temiendo el ataque de los leones que rondaban a menudo la caravana. Atravesaron diversas ciudades, algunas en ruinas, y llegaron a la corte del sultán, pero tiempo después fueron solicitados por el bajá turco de San'a, en el Yemen, pues los turcos reclamaban a todo portugués que cayera prisionero. Allí permanecieron hasta que se les destinó a galeras en Moka, de donde, finalmente, fueron rescatados a expensas del rey de España, llegando de nuevo a Goa a finales de 1596.

Tan pocas líneas para tanto espacio y tiempo. Lo que significó para los dos padres este viaje fue ante todo disciplina, aprendizaje y una manera diferente de llevar la palabra, el consuelo y el ejemplo a los prisioneros portugueses que encontraron, ganándose la admiración y el respeto de sus carceleros. Y no se desanimaron, al contrario, cobraron nuevas fuerzas. Aunque ya no le llegaron al padre Montserrat, que fallecería al poco tiempo en Goa (1599) sin haber logrado entrar en Etiopía.

Páez sufrió a su vez diversas convalecencias antes de aventurarse de nuevo a cruzar el mar y ser rechazado por varias tempestades, pero no se desanimó y en 1603 llegaba por fin a Etiopía. Esta vez, acompañando a su disfraz de armenio, le ayudaron su conocimiento del árabe aprendido durante su cautiverio y el ir solo para trabar conocimiento y amistad con un turco que prometió llevarle a Suakin, con la intención de seguir hacia el norte y volver a su supuesta patria, y que accedió a desembarcarle de camino en Massawa, aparentemente para recoger allí las pertenencias de ciertos jesuitas muertos. En esta ocasión no hubo tropiezos y una vez en Massawa envió noticias suyas al padre Melchor da Silva de la misión de Fremona. Se internó en el país y llegó a Debaroa, capital de la provincia de Tigré, y desde allí, escoltado por portugueses al servicio del Negus, el rey etíope, siguió camino hasta Fremona ${ }^{10}$. Fueron jornadas agotadoras, pero por fin estaba en Etiopía.

Su verdadera labor, o al menos para la que se había preparado durante tanto tiempo, empezaba ahora. Y no sería algo fácil. El cristianismo alejandrino monofisita y ascético que imperaba en Etiopía tenía demasiados 
siglos de tradición y costumbres arraigadas como para desplazarlo con el catolicismo de Roma ${ }^{11}$. Y sin embargo lo consiguió en parte. Su alegre personalidad, su excelente formación, su manera de tratar, escuchar, hablar, aceptar y, sobre todo, su rápido aprendizaje de las lenguas del lugar y la disposición a enseñar en cualquier campo -desde el teológico al arquitectónico- le hicieron granjearse el respeto y la amistad. Supo llegar a los corazones de quienes le trataban y, como sabía que ganar a un rey era ganar a muchos súbditos, consiguió también llegar a la realeza, que ante las noticias que le llegaban le hizo llamar en todas las ocasiones. Y éstas fueron varias, Páez conoció a tres reyes sucesivos -Jacob, Za Dengel y Socinios o Susinios-, y se ganó el afecto de todos ellos, convirtiendo además a los dos últimos al catolicismo. No quiere esto decir que hubiera ganado la batalla. Za Dengel cayó víctima de su imprudencia al enfrentarse al clero tradicional, que lideró a sus enemigos y logró su muerte. Susinios supo mantenerse entre dos aguas en su vida pública, pero tras la muerte de Páez, las acciones contraproducentes de Alfonso Mendes y las manos de su débil heredero Fasilides, a quien dejó el trono en vida, facilitaron que los poderes religiosos etíopes supieran hacerse de nuevo con la influencia necesaria para volver al antiguo estado de cosas. La situación llegó a tal punto que los católicos pasaron a ser perseguidos y ajusticiados, y los jesuitas finalmente expulsados. Pero nada de esto vio Pedro Páez, que pasó los últimos diecinueve años de su vida entregado a su labor sin salir jamás de Etiopía y que llegó a convertirse a menudo en un consejero tan personal que el rey le hacía llamar constantemente a su lado cuando debía tomar importantes decisiones políticas, incluidos los sucesivos y vanos intentos epistolares al rey español y al Papa solicitando soldados y religiosos, e incluso para que le asistiera en las numerosas batallas internas que tuvo que entablar a lo largo de todo su reinado ${ }^{12}$.

$\mathrm{Su}$ muerte fue suave. Recién acabado su libro, surgido en parte para rebatir las ideas equívocas y fantasiosas que cierta publicación del padre Urreta estaba extendiendo acerca de Etiopía ${ }^{13}$, más cargado de trabajo que nunca en su labor misionera y de atención a los necesitados, parece que fue atacado por unas fiebres fortísimas, quizá la malaria, de las que no se recuperó. Agotado, fallecía en mayo de 1622.

\section{Su manuscrito}

Pocos meses antes había terminado su libro Historia Aethiopiae y sólo hacía unos días que firmara la carta, en cierto modo prólogo, que dirigió 
El padre Pedro Páez. El primer viajero europeo conocido...

al general de la Compañía de Jesús en Roma ${ }^{14}$. Había escrito en portugués, quizá por deferencia a sus superiores en Goa o por sus estudios en Coimbra. Aunque indistintamente pudiera escribir también en español, latín, árabe o incluso en las lenguas etíopes como el amárico y el gue'ez, la lengua de los textos sagrados y de las crónicas reales, que aprendió en poco tiempo tras su llegada. De hecho había escrito en amárico dos libros de religión, un diccionario y una gramática, y tradujo un catecismo portugués para los niños ${ }^{15}$. Pero su gran obra, que en cierta manera compendiaba a las demás, fue su manuscrito Historia Aethiopiae.

No se trataba sólo de una historia, incluía también, a modo de enciclopedia de Etiopía, datos sobre la geografía, la geología, la fauna, la flora, las costumbres, la religión, las leyendas, todo lo que hubiera tenido a su alcance y sus observaciones o las de gente en la que confiaba. Mostrando un estudio antropológico y etnológico, salvando las distancias, al presentarnos las muchas tribus que habitaban el país y entre las que trabajó sin descanso. No quería repetir el error del padre Urreta, que decía escribir según lo que le había contado un etíope al que había conocido en uno de sus viajes y que, obviamente, se había entregado a fantasear del modo más descarado ${ }^{16}$. Tampoco se ceñía exclusivamente a la descripción de Etiopía, en su obra encontramos precisamente el relato de sus siete años de cautiverio en Arabia, desarrollado entre los capítulos XV y XXI de su libro III, como prólogo a su entrada en Etiopía, a la que seguía una crónica de la labor jesuita en el país desde que habían llegado. Fue además un trabajo de investigación, puesto que aprovechando su proximidad con el rey Socinios consiguió el permiso de éste para consultar los antiguos libros etíopes, tanto crónicas como libros religiosos ${ }^{17}$. Pudo así entrar donde para muchos ha estado vedado durante siglos y hacerse con información directa de una historia que podía leer él mismo, gracias a su conocimiento de las lenguas del lugar, evitando tergiversaciones de posibles traductores e intérpretes. Semejante trabajo le llevó años y en ocasiones se repetirá sobre algún tema, pero no cejará en su empeño a pesar de todas las interrupciones que le impondrán su labor de sacerdote y también la asistencia cada vez más continua al monarca.

La obra está dividida en cuatro libros de contenido diverso ${ }^{18}$. En el primero de ellos habla sobre la geografía física de Etiopía, de los usos y costumbres de sus habitantes, de la constitución civil del imperio y cuenta brevemente su historia siguiendo la crónica etíope desde sus orígenes, leyendas incluidas, hasta las victorias portuguesas de mediados del siglo XVI reinando el Negus Claudio. El segundo libro trata sobre la religión en Etiopía, de los ritos y de las ceremonias eclesiásticas, de los monjes y 
de los principales santos de Etiopía. El tercero refiere la historia de los emperadores de Etiopía y la relación de los comienzos de la misión jesuita hasta la liberación de él mismo y del padre Montserrat de manos de los turcos y su entrada final en Etiopía. Y el cuarto finalmente lo dedica a los tres últimos emperadores, que fueron los que él conoció, y a los trabajos de los jesuitas en Etiopía hasta 1620.

Probablemente, el manuscrito original fue enviado a Goa tras su muerte y quizá sea ese el que se conserva en Braga. Copia de él se halla también en Roma, cuya publicación por Beccari (1905-1906) permitió volver a acercarse a la persona de Páez, que desde su muerte había sido, si no olvidado, sólo mencionado, recogiéndose fragmentos sueltos de su obra en escritores posteriores (Lobo, 1640; Almeida, 1660; Kircher, 1678 ${ }^{19}$ ), que a su vez fueron reutilizados como referencia por otros autores y exploradores centrados en los viajes de los jesuitas $\mathrm{y}$, en concreto, en Etiopía $^{20}$.

\section{Descubridor de las fuentes del Nilo}

Etiopía era, desde épocas antiguas, el lugar del nacimiento del Nilo. $\mathrm{O}$ al menos así lo creían entonces y, del Nilo Azul, era verdad. De hecho, la gran preocupación de los turcos, que controlaban el mar Rojo, era en gran manera que el reino cristiano etíope pudiera cortar o desviar las fuentes del Nilo, con lo que ello supondría para Egipto. Se fraguaban historias al respecto y se afirmaba que realmente los reyes etíopes intervenían cuando el Nilo bajaba con poca agua. Se ha visto que no era posible, pero el temor persistía y el hecho de que fuera un reino cristiano, por tanto enemigo, aunque aislado desde hacía mucho de Alejandría y de todo trato con el Mediterráneo, hizo que se atacasen sus fronteras en repetidas ocasiones. A ello se debe la intervención de los portugueses en 1541 con Cristóbal de Gama al frente.

No se trataba de una ayuda desinteresada. Desde siglos atrás circulaba por Europa una extraña historia referente a un llamado Preste Juan de un remoto reino cristiano dispuesto a colaborar en la lucha contra el infiel $^{21}$. La leyenda se había tejido en torno a unos rumores llegados de Siria en 1145 y especialmente por una serie de cartas recibidas en 1165 por el Papa Alejandro III y por los emperadores Manuel Commeno de Constantinopla y Federico Barbarroja que todos habían tomado como auténticas, aunque su vaguedad a la hora de describir tal reino y su situación geográfica, así como a su gobernante permitiría a cualquiera du- 
El padre Pedro Páez. El primer viajero europeo conocido...

dar de ellas. Dichas cartas fueron tomadas en serio y se enviaron embajadas y expediciones con la intención de recabar su apoyo contra los musulmanes, en concreto contra los turcos, y su adhesión a la Iglesia de Roma. De esta manera, aunque en un principio se situó al Preste Juan en algún lugar de Asia Central u Oriental, el conocimiento de un reino cristiano hasta cierto punto aislado en África Oriental, hizo pensar a todos que era ese realmente el reino que buscaban. Y los portugueses, deseosos de proteger sus rutas hacia la India y el lejano Oriente, se aprestaron a despachar embajadas (Juan II de Portugal enviará a Alfonso de Paiva y Pedro de Covilhão en $1487^{22}$ ) que, dicho sea de paso, no fueron tomadas en consideración hasta que la amenaza turca se hizo evidente y realmente peligrosa. La intervención portuguesa tuvo éxito y los portugueses se quedaron, aunque nunca se logró lo que en principio se había venido a buscar, una alianza entre iguales y la protección etíope a los enclaves portugueses de la costa -bastante tenían por otra parte con protegerse ellos mismos y con mantener el orden interno del país, constantemente amenazado por revueltas de distintas facciones y tribus-. Y con los soldados portugueses llegaron las misiones. Los jesuitas hicieron su aparición en 1554 a instancias del Papa Pablo III, deseoso de establecer contacto con este reino cristiano, aunque herético por su monofisismo. Allí vino a tomar el relevo el padre Páez en 1603.

El padre Páez no encontró al Preste Juan, aunque en ocasiones se refiriera al rey como a tal, pero sí halló buen recibimiento y amistad, gracias a su carácter, y ello le valió entre otras cosas que el rey solicitara a menudo su compañía en sus traslados y campañas. Sería así como el 21 de abril de $1618^{23}$, acompañando al rey en una expedición punitiva a la región de Gojam, acamparon junto al monte Ghish, donde se decía que estaban los manantiales del Nilo Azul, y Páez decidió subir a comprobarlo en compañía de algunos hombres del emperador.

Fue así como llegó finalmente a las famosas fuentes del Nilo Azul que describe en el capítulo XXVI del libro primero de su Historia Aethiopiae. El lugar mostraba dos uolhos redondos de quatro palmos do largo». Y el humilde Páez confiesa en esta ocasión haberse alegrado al ver lo que personajes como Ciro, Cambises, Alejandro Magno o Julio César habían deseado contemplar muchos siglos atrás. Un pequeño punto de orgullo y exaltación que pronto deja paso al Páez de siempre, observador y racional, que intenta comprobar la profundidad de las fuentes con una vara, sugiere un lago interior como posible origen, relata lo que quienes están con él le cuentan sobre la naturaleza del terreno y sobre ciertos ritos que se llevaban a cabo sacrificando una vaca 
-cuya cabeza tiraban al fondo-y, en fin, describe todo el paisaje de los alrededores y los caminos de acceso, así como las variantes según la estación del año en que se encontraran y el recorrido hasta llegar al río Nilo en sí, detallando a su vez sus primeros tramos y las causas de la inundación anual. Se hace eco también de los escritos de autores conocidos como Aristóteles o del ya nombrado padre Urreta a los que corrige en sus afirmaciones, especialmente a este último, aunque le disculpa por la gran afición a la fantasía que tienen los etíopes y la poca credibilidad que se le podía dar al que informó al padre Urreta. Vuelve pues a su labor de testigo fiel y recopilador de información, capaz de poner en duda sin avergonzarse aquello que le resulta extraño o falto de toda lógica y concluye el episodio del Nilo en lo que a él se refiere. Otros temas pasan a ocupar su interés.

El padre Lobo repetirá la excursión pocos años después, en 1626, y ya no será hasta la llegada de James Bruce en 1770 que se hable de nuevo sobre las fuentes del Nilo Azul, aunque mayormente sea para ironizar la autoría del descubrimiento que asume Bruce $^{24}$.

\section{El Oriente del padre Páez}

Dada la personalidad del padre Páez hay cierta inclinación, a la que no escapamos, por reflejar su vida y obra allá donde más las desarrolló, en Etiopía. Pero no fue sólo allí donde destacó su espíritu y su forma de ser. Su aventura en Oriente comienza desde el momento en que se embarca en Lisboa rumbo a la India.

\subsection{La navegación a Goa}

A finales del siglo XVI, un viaje a la India bordeando el continente africano y atravesando el Índico no tenía nada de nimio. No se trataba sólo de la ausencia de puertos seguros en el camino, de las tribus hostiles, del encuentro con los turcos y con los holandeses y todo aquel que buscara un beneficio por aquellos mares, sin hablar de las tempestades o de la calma absoluta, de las corrientes y de los monzones; eran también los barcos en sí, que tardaban meses en llegar y cuyas condiciones a bordo eran cualquier cosa menos sanas y confortables. Las cifras hablan por sí solas: la pérdida de vidas humanas podía alcanzar al cincuenta por ciento de la tripulación y el pasaje ${ }^{25}$. 
El padre Pedro Páez. El primer viajero europeo conocido...

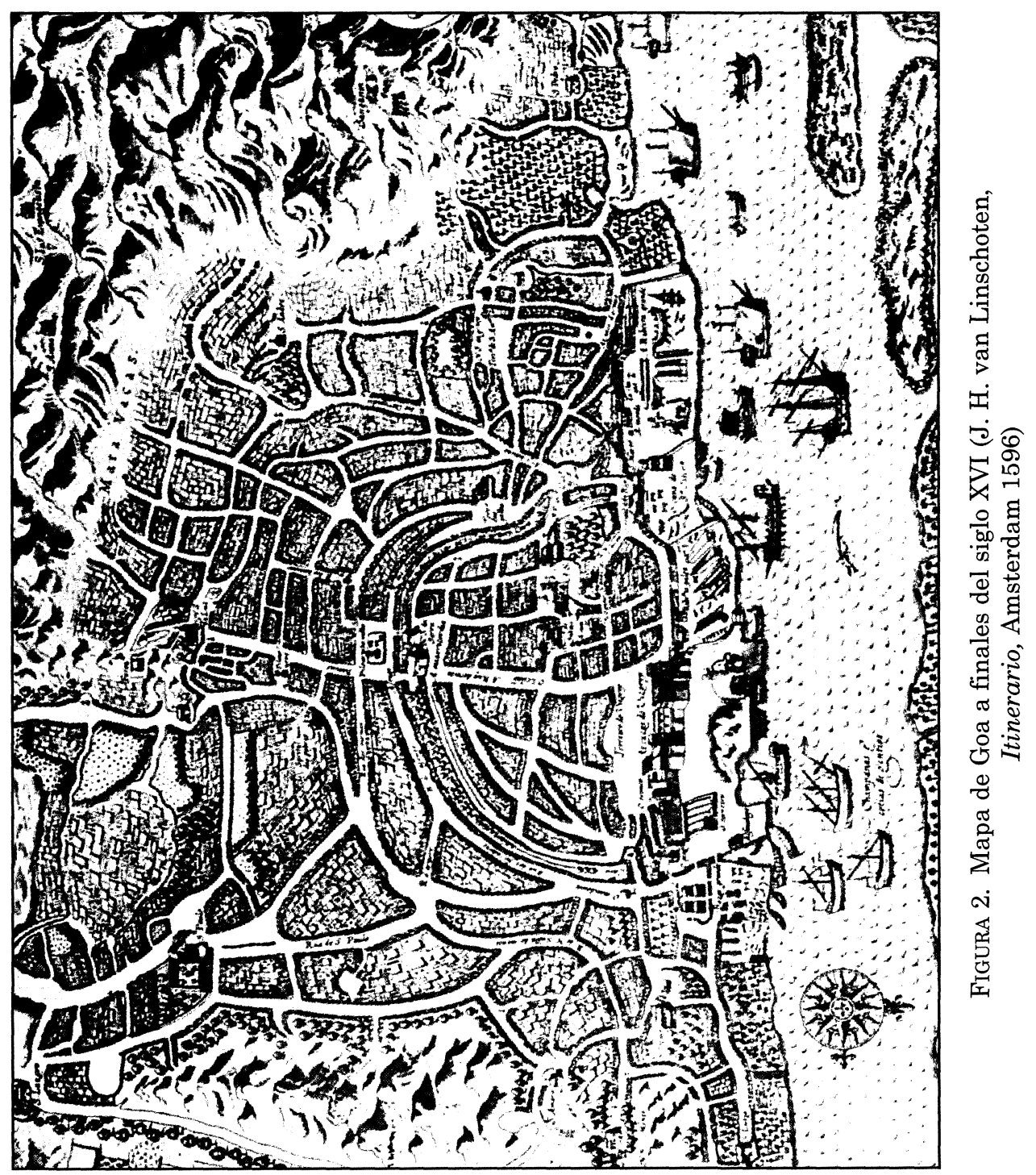


También y aun a pesar de que la navegación portuguesa tuvo un rápido desarrollo, el desconocimiento inicial de los mares, de sus corrientes y de los vientos favoreció los naufragios de modo habitual, hasta el punto de que los relatos sobre los mismos, verídicos o inventados, crearon un tipo de literatura de gran éxito ${ }^{26}$. La llamada $\mathrm{Ca}$ rreira da Índia era una auténtica carrera contrarreloj para sobrevivir. Pedro Páez fue de los afortunados y, aunque enfermó varias veces a lo largo del viaje, arribó a Goa en octubre de 1588, tras más de siete meses de travesía.

Llegar a Goa significaba haber superado lo más duro y encontrar al final del camino una verdadera ciudad, perfectamente organizada al modo europeo, aunque mantuviera el exotismo de gran parte de sus habitantes nativos y de las costumbres locales. Los relatos de los misioneros jesuitas, que escribían auténticas crónicas a sus superiores, o de viajeros como Fernão Mendes Pinto ${ }^{27}$, John Huyghens van Linschoten $^{28}$, Pietro della Valle ${ }^{29}$ o García de Silva y Figueroa ${ }^{30}$, así como los documentos de Estado propiamente dichos, nos dejan una visión bastante exacta de lo que debió ser esta ciudad enclavada en una pequeña isla de la costa india y cuya magnificencia en cuanto a calles, edificios y organización administrativa y también religiosa -no hay que olvidar que las misiones estuvieron presentes casi desde el principio-, hacía que la comparasen con las mejores ciudades de Europa ${ }^{31}$. Ésta fue la ciudad que encontró Páez, cuya decadencia no comenzó hasta mediados del siglo XVII, cuando el peligro de los ataques holandeses e ingleses hizo que se trasladara la capital a la cercana $\mathrm{Pa}$ naji, que se hallaba mejor protegida.

\subsection{El sur de Arabia y el valle del Hadramaut}

De Arabia apenas se conocían sus costas y los enclaves portugueses próximos al Golfo Pérsico. Pero allí iba a desembarcar Páez por fuerza antes de alcanzar su meta final. Partió de Goa el 2 de febrero de $1589^{32}$ con la intención de llegar a Etiopía. Junto a él marchaba un sacerdote más viejo y experimentado, el padre Antonio de Montserrat, que ya había visitado la corte del Gran Mogol, al norte de la India, y que hablaba árabe. El primer tramo del viaje era corto, hacia el norte, hasta Bassein. Allí tenían casa los jesuitas y Páez celebró su primera misa. Mientras esperaban un barco, Páez comenzó a aprender persa, que pronto dominaría. Disfrazados de armenios llegaron a Diu, 
El padre Pedro Páez. El primer viajero europeo conocido...

aún en la costa india, donde al cabo de varias semanas un barco armenio se ofreció a llevarlos hasta Mascate, en la costa árabe, para luego subir por el Golfo Pérsico hasta Basora. Este rodeo les permitiría llegar vía Iraq, Siria y Egipto hasta tierras etíopes. No había otro medio y aceptaron, pero al llegar a Mascate, el capitán decidió no seguir y hubieron de esperar de nuevo. Entre tanto pasaron a Ormuz, donde se alojaron con los padres agustinos varios meses y guardaron cama debido a las fiebres. Entonces un mercader árabe se ofreció a llevarles hasta la costa somalí. Pero al poco de zarpar les atacaron los piratas y sólo quedaron libres tras un costoso rescate pagado por el capitán del barco. Nuevamente esperaron en Mascate, sufrieron nuevos accesos de fiebre y por fin partieron rumbo a Somalia. Y entonces fue una tormenta la que desarboló el barco y les hizo refugiarse en las islas Kuria, frente a Omán. Aquí empezó su calvario de siete largos años. Al hacerse de nuevo a la mar, delatados por un árabe que les reconoció en las islas como portugueses, fueron alcanzados por dos naves turcas, descubiertos, interrogados y encerrados en Dhofar.

El capitán de Dhofar no se decidió a matarlos y los envió al interior, a su rey. De este modo comienza su viaje por el desierto, en condiciones durísimas, apenas alimentados -aunque igual podía decirse de quienes les llevaban, cuya comida solía incluir langostas, saltamontes del desierto, que los prisioneros rechazaban-, andando la mayor parte del camino -sobre todo Páez, pues a Montserrat, dada su edad y estado finalmente le hicieron subir a un camello-, sufriendo los espejismos por falta de agua, las tormentas de arena y el sol, sin apenas protección en sus cabezas, hasta llegar a la ciudad de Tarim, donde las gentes les apedrearon y sus guardianes tuvieron que esconderlos, de modo que las siguientes poblaciones decidieron cruzarlas de noche. En una de ellas serían recibidos amablemente por un hermano del rey, quien les daría la ocasión de probar una bebida desconocida, el café -câhua-, de la que Páez describe su preparación y la fruta -bun- con que la hacen ${ }^{33}$. Al día siguiente llegarán donde el rey o sultán, quien les recibirá bien y conversará con ellos, mostrando al final deseos de dejarlos libres, pero a la espera de consultar a los turcos, a los que pagaba tributo. Entre tanto, Páez no pierde el tiempo y registra todo lo que ve sobre vestimentas, cultivos, costumbres religiosas, en fin, todo lo que llega a sus ojos y oídos. Pero pasados cuatro meses los reclamará el bajá o pachá turco del Yemen, dejándolos marchar el sultán con gran pesar. Cruzan entonces una parte del desierto del Rub'al Khali o espacio vacío y llegan a Marib, cuyas ruinas 


\section{Montserrat Mañé Rodríguez}

le causan gran impresión y más cuando le cuentan que fue una gran ciudad de la reina de Saba, de donde dicen que salió para ir a ver al rey Salomón -rompiendo con las leyendas etíopes ${ }^{34}$-. Continúan hacia San'a, donde les consideran espías portugueses, aunque sus respuestas les satisfacen. Cerca de un año permanecerán en prisión en compañía de veintiséis portugueses y cinco cristianos indios a los que llevarán consuelo espiritual y psicológico, pues lograrán que colaboren entre sí en lugar de pelear a cada momento, para asombro de los propios carceleros. Poco a poco se ganarán el respeto de los turcos, que les quitan las cadenas, les permiten trabajar en el jardín o fuera y les trasladan a un lugar más espacioso donde celebrarán misas y rezos libremente, en parte porque muchos de los turcos del lugar eran antiguos cristianos, incluido el bajá que era albanés. Páez aprovechará además para aprender árabe. Despertarán también la curiosidad de la mujer del bajá, hija de cristianos, que se interesa por ellos e intercede para que se les deje marchar libres a Jerusalén; pero cuando están preparados para salir, un mercader indio de origen albanés pero que odia a los cristianos asegura al bajá que podría cobrar un gran rescate por ellos y vuelven a encerrarlos hasta que la llegada de un turco de origen sevillano, muy respetado, que desea conversar con ellos, les aligera la prisión. Páez nos relata estas conversaciones y las disputas teológicas que se llevan a cabo con distintos personajes de la ciudad, en las que siempre vencen con su conocimiento y su saber argumentar. En varias ocasiones se intenta ayudarles a marchar o recatarles de alguna manera, pero las cosas se complican, el bajá recela que no le engañen sobre lo que puede ganar con ellos y continúan en San'a, aunque con más libertad de movimientos, hasta que finalmente se les manda a Moka para servir como galeotes si no son rescatados. Así pasarán tres meses antes de que los devuelvan a tierra por enfermedad del padre Montserrat. Y estando allí llegará rescate de la India por mandato de Felipe II, quinientos cruzados por cada uno, lamentados por Páez que los habría empleado para rescatar a mayor número de cristianos, más cien chantajeados por el capitán de la galera. De este modo llegan por fin a Diu, donde serán recibidos por el padre Guardián de San Francisco y más tarde por los dominicos, los hermanos de la Misericordia y finalmente, ya en Goa, por los jesuitas en diciembre de 1596 . 


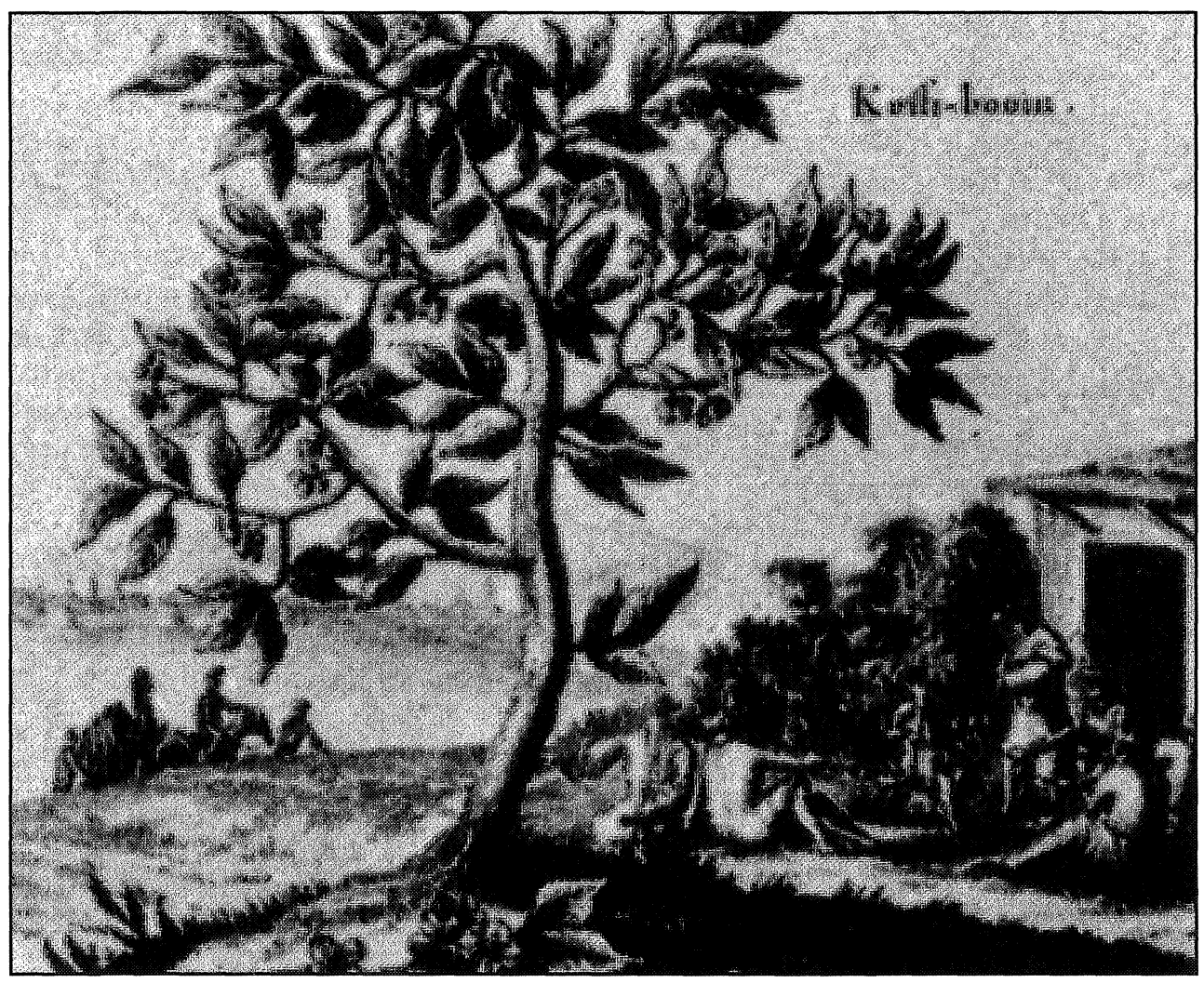

Figura 3. Planta de café según un grabado de 1680

(R. Bidwell, 1994) 
Páez no descubrió la región del Hadramaut, pero sí fue el primer europeo que nos dejó una descripción de aquella zona, aunque la ruta exacta que siguieron no pueda identificarse del todo. Él y Montserrat fueron los únicos europeos en llegar a Marib desde el este y en alcanzar San'a desde el Hadramaut. Su relato nos cuenta las miserias de su viaje, pero sobre todo describe aquello que ve y que nos resulta de enorme interés. Se deja sorprender por el paisaje, por las duras condiciones de vida que no casan con el nombre de Arabia Felix, por los escasos cultivos, que detalla, se maravilla ante la devoción, se entretiene en mostrarnos vestimentas y peinados, nos ofrece una de las primeras menciones del café que se conocen, se interesa por las ruinas de edificios antiguos y nos da una visión de los árabes más tolerante con los cristianos de lo que se pensaría en un principio -eran realmente los turcos quienes sentían más animosidad-. Su curiosidad no tiene límites y su capacidad de aprendizaje tampoco. No sabemos si nos maravilla más el recorrido que realiza, por ser el primero que lo lleva a cabo y lo escribe, o su personalidad.

\section{Epílogo}

Hemos visto de qué pasta está hecho Pedro Páez. No sabemos si de haberse quedado en España o Portugal habría sido de otra manera. No lo parece. En todo momento su gran presencia de ánimo y una fe inquebrantable le permiten mirar a su alrededor y olvidarse de sí mismo. A lo largo de su cautiverio no se entretiene en sus dolencias más que lo justo y algo más en las de su compañero, pero sí observa el entorno, las gentes y los lugares. Está en un país nuevo y en una situación nueva, y saca el máximo partido de ello. No se encierra en sí mismo, es positivo y transmite esa forma de ser a todo el que trata con él. Y da igual las penalidades que pase o, por el contrario, los favores que reciba, él se mantiene siempre ecuánime y rara vez se deja llevar de un entusiasmo excesivo o de una cierta melancolía. Su narración es desapasionada y sin embargo nos transmite la necesidad de seguir adelante, de ver lo que viene después, por desesperada que sea la situación, porque confía plenamente, jamás se siente abandonado gracias a su fe. Podría ser la imagen que en ocasiones tenemos del explorador entusiasta, pero no es así. Sus descubrimientos, en parte forzosos, le llenan de alegría o simplemente le maravillan, pero no son su meta, de ahí que nos lleguen en un primer momento en un tono apagado y sólo las reivindicaciones posteriores hagan resaltar su nombre, aunque es claro que él sería el primer sorprendido y 


\section{El padre Pedro Páez. El primer viajero europeo conocido...}

rechazaría a gusto la importancia concedida a estos hechos a cambio de que su obra evangélica se hubiera perpetuado.

Quizás no podamos hablar de un gran descubridor, al menos conscientemente, sino de un gran hombre. Lo que significó para el conocimiento de Arabia y África Oriental podemos evaluarlo hoy a grandes rasgos, pero lo que realmente llevó a cabo fue una labor humanitaria y religiosa de un alcance desproporcionado para las fuerzas con que en principio contaba. Que su trabajo no perdurara más allá de su vida estaba fuera de su alcance. Hoy lo que nos queda es ese espíritu emprendedor y unos hechos inamovibles que generalmente son los que escriben la historia: cruzó y describió por primera vez el valle del Hadramaut y nos dejó una visión desconocida hasta entonces de las gentes que lo poblaban, y además vio las fuentes del Nilo Azul y fue el primero que dejó constancia de ello por escrito y con gran riqueza de detalles. Y, por si no bastara con ser el primero, nos añadió toda una crónica del país por el que cruzó medio mundo y al que dedicó sus últimos diecinueve años de vida. Semejante entrega, se mire por donde se mire, bien vale un recordatorio, aunque sea a título póstumo.

\section{Bibliografía}

Almeida, E. DE (1660: 1907-1908): História Geral de Ethiopia a Alta ou Abassia En Rerum Ethiopicarum Scriptores Occidentales inediti a saeculo XVI. ad XIX... Beccari (Ed). V-VII, Roma.

ANDRADE, P. (1887-1892): «P. Pedro Páez, llamado apóstol de Etiopía» En Varones ilustres de la Compañía de Jesús Vol. II, 472-507.

BECCARI, C. (Ed.) (1903-1917): Rerum Ethiopicarum Scriptores Occidentales inediti a saeculo XVI. ad XIX... I-XVI, Roma.

BECKInGHAM, C. (1949): "Some early travels in Arabia» The Journal of the Royal Asiatic Society of Great Britain and Ireland October 1949, 155-176.

- (1966: 1983): "The Achievements of Prester John" An Inaugural Lecture delivered on 17 May 1966 at the School of Oriental and African Studies, en Between Islam and Christendom. Travellers, Facts and Legends in the Middle Ages and the Renaissance,Variorum Reprints, London, 3-24.

Beckingham, C. \& SerJeant, R. B. (1950): «A journey by two jesuits from Dhofar to San'a in 1590" The Geographical Journal 115, $\mathrm{n}^{\circ}$ 4/6, 194-207.

BIDWELL, R. (1994): Travellers in Arabia Garnet, Berkshire.

Bishop, G. (1998: 2002): Viajes y andanzas de Pedro Páez. Primer europeo en las fuentes del Nilo (1613) Mensajero, Bilbao.

Boxer, C. R. (1975) : The Portuguese seaborne empire: 1415-1825. Alfred A. Knopf, New York.

Castanhoso, M. DE (1564: 1988): História das cousas que o mui esforçado capitão Dom Cristóvão da Gama fez nos Reinos do Preste João com quatrocentos Portugueses que sonsigo levou Europa-América. Col. A Aventura Portuguesa, 4, Lisboa. 
Chandeigne, M. (Ed.) (1990: 1992) : Lisboa Extramuros 1415-1580. El descubrimiento del mundo por los navegantes portugueses Alianza Editorial, Madrid.

- (Dir.) (1996) : Goa 1510-1685. L'Inde portugaise, apostolique et commerciale Autrement, Paris.

Contente Domingos, F. (1990: 1992): " Navíos y marineros», 56-70. En Lisboa extramuros 1415-1580. El descubrimiento del mundo por los navegantes portugueses Chandeigne (Ed.), Madrid.

DÉCOUVERTE DE L'ÉTIOPHIE CHRÉTIENNE (1975) Monográfico de Les dossiers de l'Archéologie 8, Janvier-Février 1975.

GiLliot, C. (1998): «Die Königin von Saba’ - Legende oder Wirklichkeit?» Jemen. Kunst und Archäologie im Land der Königin von Saba' Katalog der Ausstellung im Kunsthistorisches Museum, 9. November 1998 bis 21. Februar 1999, Wien, 41-45.

LANDSTRÖM, B. (1964: 1971): En busca de las Indias Juventud, Barcelona.

LiBois, C. (2001): «Los Jesuitas en Etiopía: Las Fuentes del Nilo Azul. Pedro Páez (1613)» En Exploradores españoles olvidados en África Sociedad Geográfica Española, Madrid (www.sge.org/sge07/03/fuentes_del_nilo.asp).

Lово, J. (1640: 1971): Itinerario e outros escritos inéditos Companhia Editora do Minho, Barcelos.

MARÍAS, F. (2002): «Don García de Silva y Figueroa y la percepción del Oriente: la 'Descripción de Goa'» Separata del Anuario del Departamento de Historia y Teoría del Arte (U.A.M.) 14, 137-149.

Mendes Pinto, F.(1614: 1982): Las Peregrinaciones Alfaguara, Madrid.

PÁEZ, P. (1622: 1905-1906): Historia Aethiopiae En Rerum Ethiopicarum Scriptores Occidentales inediti a saeculo XVI. ad XIX... Beccari (Ed). II-III, Roma.

REverTe, J. (2001): Dios, el diablo y la aventura Plaza-Janés, Barcelona.

Soler, I. (2004): Los mares náufragos Acantilado, Barcelona.

SouzA, T. R. DE (1994): Goa medieval. A cidade e o Interior no Século XVII Estampa, Lisboa.

TEYssiER, P. (1990: 1992): "Los cien gloriosos», 14-54. En Lisboa extramuros 1415-1580. El descubrimiento del mundo por los navegantes portugueses Chandeigne (Ed.), Madrid.

VARONES ILUSTRES DE LA COMPAÑ́́A DE JESÚS (1887-1892). Mensajero del Corazón de Jesús, Bilbao.

\section{Notas}

1 En 2003, el 400 aniversario de su primer viaje a Etiopía junto al recientemente aparecido libro de Javier Reverte (2001) han hecho que se recupere en parte su memoria, llegando incluso a organizarse una expedición (http://www.sge.org/sge03/pboletin9ar.asp) que ha seguido sus huellas, filmando un documental dirigido por el propio Reverte (http://www.rtve.es/tve/programo/avan4/tv4s0703.htm), pero olvidando lo que fue su existencia previa a la entrada en Etiopía. También los Misioneros Combonianos han tenido un reciente recuerdo para él (P. Juan González Núñez, Mundo Negro 492, enero 2005; www.combonianos.com/mn/enero/pedropaez.htm) y, en general, van saliendo pequeños textos en los que se hace referencia a tan señalado personaje.

2 Bishop, 1998: 211-224. Nos referimos, claro está, al británico James Bruce (Travels to discover the source of the Nile, in the years 1768-1773 Edimburgo, 1790) que no sólo se 


\section{El padre Pedro Páez. El primer viajero europeo conocido...}

adjudicó tal descubrimiento al llegar en 1770, sino que se dedicó a difamar a Páez y a los jesuitas que le siguieron, especialmente al padre Jerónimo Lobo que siguió en pocos años al padre Páez (Lobo, 1640).

${ }^{3}$ Herodoto se aventuró hasta la primera catarata en el siglo V a.C. Eratóstenes dibujó un mapa hasta Jartum en el siglo III a.C. Nerón en el siglo I d.C. envió soldados que no alcanzaron más que las regiones ya conocidas. Ptolomeo, en el 150 d.C., dibujó a partir de relatos que llegaron a sus oídos un mapa relativamente exacto, que sirvió de guía a los viajeros posteriores, en el que se veían lagos y montañas nevadas.

${ }^{4}$ Lobo, 1640. Su llegada, a los pocos años de morir Páez, nos permite conocer la labor de su sucesor el padre Alfonso Mendes, hombre de gran fe, pero intransigente, que no supo comprender el espíritu de las gentes de Etiopía, se granjeó su animadversión y logró desbaratar toda la labor y el respeto que Páez había logrado. Lobo será testigo de la expulsión de los jesuitas en 1633.

Reverte, 2001: 229-231.

5 Almeida, 1660.

6 Nombre que cambió en 1954 a Olmeda de las Fuentes a petición del propio pueblo (www.olmedadelasfuentes.org). Actualmente pertenece a la Comunidad de Madrid, habiendo dependido antaño más directamente de Alcalá de Henares.

7 Chandeigne, 1996. No hay que olvidar que las misiones de China y Japón conectaban con Europa a través de la India -de allí partieron Mateo Ricci para China y Francisco Javier para Japón-. No hacía muchos años, en 1554, que, por ejemplo, el jesuita Francisco Javier -canonizado con Ignacio de Loyola el año de la muerte de Páez- había sido enterrado allí tras peripecias varias para traer su cuerpo desde el Extremo Oriente (Mendes Pinto, 1614; 1982: 848-856). En Goa había desarrollado parte de su importante labor aunque sus estancias allí fueran cortas.

${ }^{8}$ Beccari, 1905: XI. Su primera carta al padre Ituren, fechada al parecer en febrero de 1589, nos resume esa petición, así como nos describe elogiosamente a su compañero de viaje y los trámites que siguieron, entre ellos la aceleración de su ordenación sacerdotal antes de partir. La fecha de partida no está muy clara, Beccari cree que Páez, que escribe su viaje años después en Etiopía, se equivoca en un año, siendo en ese caso 1589 el año correcto.

9 Bidwell, 1994: 105-113, 163-164, 178-189. Aunque algunos viajeros europeos alcanzaron el Hadramaut ya en el siglo XVIII -como los alemanes Adolf von Wrede (Reise in Hadhramut Brunswick, 1870) y Leo Hirsch (Reisen in Südarabien, Mahra-Land und Hadramaut Leipzig, 1897) o los británicos Mabel y Theodore Bent (Southern Arabia London, 1900)-, no fue hasta los años 30 del siglo XX que John Philby (The Empty Quarter London, 1933) cruzó realmente el sur de Arabia siguiendo una ruta similar.

10 Castanhoso, 1564. Desde que en 1541 don Cristóbal de Gama, con más de cuatrocientos voluntarios portugueses, acudiera en auxilio del rey etíope amenazado por los turcos, siempre hubo portugueses a su servicio. Pues los supervivientes, al parecer unos ciento treinta, ya no marcharon y se establecieron allí formando una especie de cuerpo de élite de la realeza que fue mestizando con el tiempo al casarse con mujeres locales y tener descendencia.

Lobo, 1640: 403-424. Dicho episodio tuvo gran trascendencia y la persona de Cristóbal de Gama, cogido prisionero, torturado y ejecutado, fue propuesta para canonización. Por este motivo, el padre Lobo, que llegaría años después y sería testigo de la expulsión de los jesuitas, recibió el encargo de encontrar la tumba de Cristóbal de Gama y recuperar sus restos. Así lo hizo en 1626 o creyó hacerlo, nunca quedó claro si los huesos que . 
halló e hizo enviar a Goa eran realmente los de este personaje. Su tumba en cualquier caso quedó en las cercanías de la ciudad de Gondar y allí la redescubrió siglos después otro viajero español, don Víctor Abargues de Sostén, en 1881 (Noticias acerca de la expedición ... Madrid, 1883: 269-270. Ver en este mismo número el artículo dedicado a su persona).

${ }^{11}$ La historia religiosa del cristianismo etíope parece que se remonta al siglo IV, cuando, tras la llegada de dos monjes -Frumencio y Edesio-, el rey Ezana de Axum se convierte y en el siglo V, los llamados «Nueve Santos», monjes sirios monofisitas, asientan definitivamente esta nueva fe y, muy importante en el futuro político, su dependencia del patriarcado alejandrino. Pero no sólo quedó arraigado este cristianismo, pues la leyenda quiere que los reyes etíopes desciendan de la mítica reina de Saba y el rey Salomón, cuyo hijo Menelik habría sido el primer rey salomónida de la dinastía y además portador de las tablas de la Ley, robadas en el templo de Jerusalem. Se juntaban por tanto tradiciones judías y cristianas, como el respetar el sábado en lugar del domingo, que permanecían tanto más clavadas en la mentalidad de la gente cuanto menor era su conocimiento real de la religión y contra eso tenían que enfrentarse los jesuitas a la hora de encaminar la fe de los etíopes. Siendo más difícil luchar contra las costumbres que contra las creencias, se necesitaba mucho más tacto para ello.

12 Etiopía nunca fue un reino en paz. Constantemente había tribus que se rebelaban en distintos puntos. El rey se encontraba en campaña casi permanente y rara vez la corte permanecía en un lugar fijo, a pesar de lo cual, Páez construyó para el rey un palacio en Gorgora, junto a una iglesia, al más puro estilo arquitectónico europeo, que fue la admiración de todo el que se acercaba a verlo. Aún hoy quedan restos ruinosos de aquella obra que parece fuera de contexto dado el entorno.

13 Beccari, 1905: vol. II, 3-4. Carta-presentación del libro de Páez al general de la orden en Roma, en la que, entre otras cosas, señala su intención de enmendar dichas ideas erróneas de la obra de Urreta.

Reverte, 2001: 214-219. El tal libro era de un dominico español, Luis de Urreta, publicado en Valencia en 1610 y que titulaba Historia eclesiástica y política de los grandes y remotos reinos de Etiopía, Monarquía del Imperio llamado Preste Juan de las Indias.

14 Ver nota 13.

15 Reverte, 2001: 121.

16 Reverte 2001: 215-216. Desde afirmar que los etíopes eran católicos -bien sabía Páez que no-, hasta, por poner algunos ejemplos, hablar de hormigas gigantes, reyes que descendían de los Reyes Magos y nacían con una estrella grabada en la piel, una biblioteca que contenía todo el saber del mundo, etc.

17 Beccari, 1905, vol. II: XXXII-XXXVIII; vol. III: III-XI. Beccari expone la lista de obras etíopes que utilizó Páez, así como las europeas, también el nombre de los que le transmitieron algún testimonio y lo que fueron experiencias propias del autor, todo ello desglosado y en orden.

18 Beccari, 1903, vol. I: 78-84. Beccari describe el contenido de cada libro y cada capítulo, previamente a la’publicación del manuscrito en los dos volúmenes siguientes, añadiendo anotaciones propias.

19 Libois, 2001. Los tres eran jesuitas. Athanasius Kircher escribió el Oedipus Aegyptiacus, en cuyo primer volumen recogía algunas de las páginas de Páez traducidas al latín (http://www.dzg.com/schwarzesbrett/reisebuecher/anzeigen.php?bu=1478

http://www.egiptomania.com/egiptologia/egiptologia_kinnaird.htm).

20 Reverte, 2001: 218-219. 


\section{El padre Pedro Páez. El primer viajero europeo conocido...}

Landström, 1964: 90-93, 138.

${ }^{21}$ Beckingham, 1966: 3-24.

${ }_{22}$ Beckingham, 1949. Francisco Álvarez nos deja la confirmación de su relato en el capítulo 104 de su Ho preste Joam das Indias. Verdadera Informaçam das terras do Preste Joam, publicado en 1540.

Landström, 1964: 216-221, 224. Se separaron en el mar Rojo, Paiva para buscar al Preste Juan en Etiopía y su compañero hacia la India. Paiva falleció antes de llegar a Etiopía y Covilhão, que no llegó hasta 1493, después de recorrer el mar Rojo, la costa sur de Arabia, la costa occidental de la India y, ya de vuelta, Mozambique, Kilwa, Mombasa y Malindi, se vio retenido por el Negus y nunca pudo volver, tan sólo una carta suya llegó a Portugal en 1491 con un informe de su viaje por India y África, antes de llegar a Etiopía, que acababa con las esperanzas de un reino cristiano dispuesto a ayudar a los portugueses.

Teyssier, 1990: 20-23.

${ }^{23}$ Por alguna razón, Bishop (1998) recoge como año de esta visita el de 1613, cuando los demás autores hablan todos de 1618. Puede que, si leyó el manuscrito original, confundiera el 8 con un 3. Curiosamente, autores posteriores como González Núñez o Reverte no hacen ningún comentario al respecto.

${ }^{24}$ Ver nota 2.

${ }^{25}$ Contente Domingos, 1990: 56-70.

Soler, 2004: 8-21.

Se nos describen las penurias vividas en estos viajes a finales del siglo XVI y a mediados del siglo XVII. El propio barco era una trampa. Los alimentos rara vez eran frescos, normalmente bizcochos, carne o pescado salados, agua y vino. Las verduras y frutas se consumían en los primeros días antes de que se estropearan y normalmente faltaban ya alimentos y agua potable a la semana, quedando sólo algunos en no muy buenas condiciones. A ello se sumaban los intereses comerciales, sobornos y demás, que hacían que muchas veces se cargaran más mercancías que alimentos necesarios. Tampoco solía haber médicos a bordo. Y a la mala alimentación se unían la falta de higiene, los gusanos en los alimentos y las ratas, cucarachas, piojos y chinches, asegurándose las enfermedades, como el temido escorbuto, y epidemias.

${ }^{26}$ Soler, 2004: 21-49.

${ }^{27}$ Mendes Pinto, 1614. Parece que pasó por Arabia, quizá Etiopía y llegó a Goa en 1538. Si bien su relato es tomado a menudo como una serie sucesiva de mentiras y verdades entremezcladas, su descripción de Goa, donde sabemos que estuvo más de una vez -en 1554 sería testigo del desembarco del cuerpo de San Francisco Javier-, concuerda con la realidad que conocemos del momento.

${ }^{28}$ Cuyo mapa de Goa fue referencia obligada. Vivió allí entre 1583 y 1589 empleado como secretario del arzobispo portugués de Goa. Su obra Itinerario se publicó en Amsterdam en 1596.

${ }^{29}$ Estuvo en Goa entre 1623 y 1624. Desde el comienzo de sus viajes, Della Valle escribió cartas a un amigo suyo de Nápoles -Mario Schipano-, que se publicaron en tres volúmenes, uno apenas dos años antes de su muerte, ocurrida en 1652, y los dos siguientes ya en 1658 (G. Gancia, Viaggi di Pietro Della Valle, il Pellegrino, 2 vols., Brighton, England, 1843).

${ }_{30}$ Marías, 2002. García de Silva y Figueroa, que permaneció en Goa unos seis años en total a lo largo de tres estancias sucesivas (1614-1617, 1620, 1621-1624), hace una descripción detallada, acompañada de uno de los mejores mapas que se conservan de Goa en 
el siglo XVII. Se detiene en cada calle, cada edificio, desde Goa la Vieja a Goa la Nueva (hoy la Vieja Goa) y algunos de los alrededores, no escatimando observaciones propias y comentarios sobre las costumbres de los nativos, creencias locales, lenguas y, en fin, sus impresiones en general, comparándolas a menudo con lo que eran sus conocimientos y experiencia europeos, a modo de estudio antropológico además de topográfico.

31 Souza, 1994.

32 Ver nota 8.

33 El botánico alemán Leonard Rauwolf se adelantó en pocos años a la descripción de esta bebida y de la planta tras un viaje por Siria en su libro Aigentliche Beschreibung der Raisz in die Morgenländer Laugingen, 1583: 102-103.

${ }^{34}$ Gilliot, 1998: 41-45. 